(C) 2021 IEEE. Personal use of this material is permitted. Permission from IEEE must be obtained for all other uses, in any current or future media, including reprinting/republishing this material for advertising or promotional purposes, creating new collective works, for resale or redistribution to servers or lists, or reuse of any copyrighted component of this work in other works

\title{
Ellipsoidal Optical Cavities for Enhanced Thermophotovoltaics
}

Nima Talebzadeh, Atousa Pirvaram, and Paul G. O'Brien

IEEE Journal of Photovoltaics

Published October 27, 2021

DOI: 10.1109/JPHOTOV.2021.3116918 


\title{
Ellipsoidal Optical Cavities for Enhanced Thermophotovoltaics
}

\author{
Nima Talebzadeh, Atousa Pirvaram, and Paul G. O’Brien
}

\begin{abstract}
Herein we present an optical cavity in the form of a prolate ellipsoid that can greatly enhance the performance of solar thermophotovoltaic (STPV) systems. The geometrical parameters of the cavity can be designed to control the degree of photon recycling, the temperature of the emitter within the STPV system, gap distance and effective view factor between the PV cell and the emitter, and to minimize the emission losses. Numerical analysis shows the ellipsoidal optical cavity can be designed to achieve an effective view factor of $88.7 \%$ between the emitter and $P V$ cell within a STPV system. Results show an efficiency of $5.62 \%$ in a STPV system with a GaSb PV cell and a black-body emitter under solar radiation at a concentration factor of 350X. Further, assuming the surface of the ellipsoidal optical cavity is capable of reflecting $99 \%$ of the radiation incident onto its surface, efficiencies of $15.54 \%$ can be attained when the solar concentration factor is $1400 \mathrm{X}$. These results are attained for STPV systems without using selective absorbers, emitters or filters. The ellipsoidal optical cavity can be integrated into the design of advanced TPV systems and bring them closer to the high theoretical efficiencies TPV systems are capable of.
\end{abstract}

Index Terms-Thermophotovoltaics (TPV), photon recycling, effective view factor, optical cavity.

\section{INTRODUCTION}

$\mathrm{T}$ HERMOPHOTOVOLTAICS (TPV) is a versatile technology with many applications including uninterruptible power supplies, self-powered heating devices and industrial waste heat recovery [1], [2]. The primary components in a TPV system are the emitter and the photovoltaic (PV) cell. The emitter operates at a temperature of $\sim 600 \mathrm{~K}$ to $\sim 2000 \mathrm{~K}$, and radiates photons that are incident onto a low-bandgap PV cell, such as InGaAs, $\mathrm{Ge}$ or $\mathrm{GaSb}$ cells. Photons from the emitter with energy above the band-gap of the semiconductor in the PV cell, referred to as in-band photons, can be converted to electric power. However, the PV cell is unable to convert photons with energy below the band-gap, which are referred to as out-of-band photons. While research interest in TPV systems has increased considerably over the last few years [3], [4], there is extensive capacity for further improvements, as TPV systems do not currently operate close to their theoretical efficiency limits [5], [6].

Advancements in TPV system performance will promote clean energy in the form of waste-heat recovery, combined heat

This research was funded by the Natural Sciences and Engineering Research Council of Canada (NSERC). (Corresponding author: Paul G. O'Brien.)

Nima Talebzadeh, Atousa Pirvaram, and Paul G. O'Brien, are with the Department of Mechanical Engineering, Lassonde School of Engineering, York and power systems, and solar thermophotovoltaics (STPV). STPV in particular has potential to improve the performance of solar energy harvesting by converting the broadband solar irradiance to a spectrum that is more favorably matched to the PV cell band gap. From a theoretical perspective, STPV can achieve an efficiency of 85.4\% [5]-[7]. From an experimental perspective, the advantages of integrating STPVs with energy storage systems have been investigated [8]-[10]. For example, Datas et al. [11] used silicon as a latent heat storage material in a highly-compact concentrated solar power (CSP) system which was capable of both thermal energy storage and electric power generation. Further, Datas et al. [12] reported on the practical implementation of a STPV system comprised of a cylindrical cup-shaped absorber/emitter. Conversion efficiencies of $\sim 0.8 \%$ were measured under outdoor conditions. The low system efficiency was attributed to overheating of the PV cells and high optical concentration losses.

In contrast to 3-dimentional cylindrical structures, STPV systems with planar architectures show better performance due to their smaller emission surface area which enables higher emitter operating temperatures. Ungaro et al. [13] experimentally demonstrated a planar STPV system with an overall power conversion efficiency of $6.2 \%$ under solarsimulated radiation at a concentration factor of $2500 \mathrm{X}$. The STPV system was operated at a vacuum pressure of $10 \mathrm{mTorr}$, and the temperature of the PV cell reached a maximum of 72 ${ }^{\circ} \mathrm{C}$. The main losses were attributed to the low efficiency of the PV cell ( $\sim 5 \%$ loss), thermal emission that does not reach the PV cell (11\% loss), and emittance from the absorbing surface (23.6\% loss). Kohiyama et al. [14] used a confined cuboid emitter/absorber surrounded by PV cells to increase the photon recycling in STPV systems. Their analysis predicted a $4.1 \%$ higher system efficiency than that attained using a planar absorber/emitter configuration. Experimental results showed system efficiencies of $7 \%$ when the input power density was 81 $\mathrm{W} / \mathrm{cm}^{2}$. Numerical analysis predicted the system efficiency could reach $20 \%$ by improving the back surface reflector and the enclosed space. Wang et al. [15] used selective metamaterials as absorber and emitter for a planar STPV system with an InGaAsSb PV cell and optimized the emitter to absorber area ratio. Their theoretical analysis revealed $12.6 \%$ efficiency at a solar concentration of $200 \mathrm{X}$, and $A_{\text {emitter }} / A_{\text {absorber }}$

University, Toronto, ON, M3J 1P3, Canada (e-mail:

nima.talebzade@gmail.com; pirvaramatousa@gmail.com; 
$=4$. Wang et al. [16] proposed a cage-type STPV in which the absorber and emitter are surrounded by PV cells. In their theoretical analysis, they used a bifunctional hybrid absorberemitter sequentially deposited by $\mathrm{HfO}_{2} / \mathrm{Mo} / \mathrm{HfO}_{2}$ films on a metallic surface. They reached to the conclusion that the cagetype STPV system can increase the system efficiency by $15 \%$ in comparison to that of ideal planar STPV system with emitter/absorber area ratio of 10. Kelsall [17] designed, fabricated and characterized a graphite-based cylindrical absorber for an STPV system with a GaSb PV cell. The STPV system was theoretically evaluated under $3600 \mathrm{X}$ Sun concentration and the analysis estimated $9 \%$ system efficiency.

To date, most research on TPV/STPV systems has focused on PV cells [18]-[25], absorbers/emitters [26]-[34], and optical filters to reflect out-of-band photons back to the emitter [31][36]. However, the design of optical cavities for STPV systems has rarely been studied, despite the fact that optical cavities can be used to increase the system efficiency, photon recycling (also known as photon recuperation or regenerative TPV [35]), and emitter-to-cell effective view factor [37], [38]. Optical cavities can be made using durable and relatively inexpensive mirror-polished metallic surfaces that direct the radiation from the emitter toward the TPV cell [39]. Sansoni et al. [40] evaluated a combustion-based TPV system in a tubular optical cavity with an elliptical cross-section. The burner was situated along one focal line within the tube and TPV cells were located along the second focal line, such that radiation emitted from the burner was specularly reflected from the inner surface of the tube toward the PV cells. Several cavity configurations were analyzed using ray tracing configurations and simulations predicted a maximum thermal emission collection efficiency of $62 \%$ when the reflectance of the cavity walls is $90 \%$. Moreover, Lindberg et al. [41] designed a wood powder-fueled TPV system consisting of an egg-shaped cone with an emitter at one end, an edge filter at the wide center, and a PV-cell array at the other end. The function of the edge filter is to reflect low-energy thermal photons back to the emitter while transmitting photons with energy greater than the band-gap energy to the PV cell. The inner surface of the cone specularly reflects radiation from the emitter to limit the angular distribution of radiation incident on the filter. This is desirable because the cut-off frequency of edge filters is sensitive to the incident angle of incoming photons.

Herein we numerically investigate the potential for using ellipsoidal optical cavities to enhance the performance of STPV systems. We investigate ellipsoidal-shaped cavities because they have two focal points, and rays emitted from one of these focal points that are specularly reflected from the internal surface of the cavity will converge onto the second focal point. Thus, the objective of this study is to numerically evaluate STPV system configurations wherein the absorber/emitter resides at one focal point and the PV cell is located at the second focal point within an ellipsoidal cavity. We determine how the ellipsoidal cavity configuration can increase the emitter-to-cell effective view factor, output power density, photon recycling capability, and decrease the emission loss and heat load on the PV cell (thereby decreasing the cooling power demand). In practice the walls of the ellipsoidal cavity can be fabricated from mirror-polished metallic surfaces. In this work we are interested in determining the extent to which the ellipsoidal cavity configuration can improve these STPV performance parameters without the use of selective absorbers, emitters, filters, or other components that are less stable at high operating temperatures. Our results show the ellipsoid-based cavity can achieve an emitter-to-cell effective view factor of $88.7 \%$. In comparison, the maximum emitter-to-cell effective view factor for an emitter and PV cell in a planar (parallel plate) configuration is $50 \%$. We also show that the number of photons reflected back to the emitter (recycled) can be controlled by either changing the ratio of the area of the PV cell to that of the absorber/emitter or by adding an annular reflector at the midplane of the ellipsoidal optical cavity. Increasing the degree of photon recycling is beneficial for increasing the emitter temperature and amount of high energy photons that can be converted to power in the PV cell. Results show the optical cavity can be designed to achieve an efficiency of $5.62 \%$ in a STPV system with a GaSb PV cell, black-body absorber/emitter and 350X solar concentration (incoming power of $28 \mathrm{~W} / \mathrm{cm}^{2}$ ) when the specular reflectivity of the ellipsoidal cavity is $95 \%$. The system efficiency increases to $15.5 \%$ by increasing the incoming solar concentration ratio and specular reflectivity of the ellipsoidal cavity to $1400 \mathrm{X}$ and $99 \%$, respectively. We also investigate the heat transfer to the cell within the STPV system at different operating pressures from 0.01 to $1 \mathrm{~Pa}$. Results show the cooling power requirement (reported in Watts) to keep the $\mathrm{PV}$ cell at a temperature of $T_{0}=300 \mathrm{~K}$ is dominated by radiative heat transfer. The effects of conductive heat transfer for the range of operating pressures considered in this work are negligible. Further, results show the ratio between the heat load (cooling requirement to keep the $\mathrm{PV}$ at $300 \mathrm{~K}$ ) and power output from the PV cell can be reduced from 19.9 for a reference STPV system (comprised of an emitter and PV cell configured as two parallel plates) to 9.36 for STPV systems comprising the ellipsoid optical cavity investigated in this work.

\section{Description Of The Optical Cavity}

An example of the ellipsoidal optical cavity investigated in this work, referred to as a Radiant Energy Spectrum Converter (RESC), is shown in Fig. 1. An innovative aspect of this optical cavity is its ellipsoidal structure, with principal semi-axis $a, b$, and $c$ and two focal points (shown as $f_{1}$ and $f_{2}$ in Fig. 1a). All thermal radiation emitted from $f_{l}$ that is specularly reflected from the internal surface of the ellipsoid converges onto $f_{2}$. As shown in Fig. 1b, a disc-shaped blackbody (BB) emitter (i.e. graphite could be used, which has emissive properties close to that of a blackbody) can be placed at $f_{l}$ to receive incident radiation that enters a port at the top of the RESC. The internal surface of the ellipsoid is coated with an IR mirror (such as Aluminum which has a reflectivity of $\sim 95 \%$ over a broad spectral range), and thermal radiation emitted from $f_{l}$ is reflected to $f_{2}$. A small bifacial PV cell situated at $f_{2}$ can absorb a large portion of thermal radiation emitted from $f_{l}$ (high effective view factor). The geometrical parameters of the RESC structure shown in Fig. 1b can be tailored to control the 
acceptance angle of concentrated solar radiation entering the cavity, the temperature of the emitter, effective view factor between the emitter and PV cell, photon recycling and the distance between the emitter and the PV cell. For example, the radius of the disc-shaped absorber/emitter, $r_{B B}$, in Fig. $1 \mathrm{~b}$ and the acceptance angle, $\theta$, can be designed to optimize the tradeoff between the incoming solar irradiance absorbed by the absorber/emitter and the emission losses exiting the opening at the top of the RESC. Also, the semi-latus rectum (the radius of the ellipse at its vertices), $p$, and the distance between the center of the ellipsoid and the PV cell, $k$, determine the number of emitted photons that are recycled back to the emitter, the emitter-PV cell separation distance, and the power delivered to the PV cell (effective view factor). Further, an annular reflector (Fig. 1c and 1d) can be added at the mid-plane of the ellipsoidal cavity to increase the photon recycling, thereby increasing the temperature of the emitter and the number of in-band photons it radiates.

The proposed RESC structure shown in Fig. 1 offers a unique combination of advantages, including a high effective spherical view factor between the emitter and the PV cell, tunable photon recycling, and a large PV cell-emitter separation distance. The high effective view factor enables large system efficiencies by low emission and reradiation losses, and using PV cells with small areas (thermal lens effect), which reduces system costs and increases output power density. The tunable photon recycling can be used to control the temperature and spectrum of the emitter and increase system efficiencies. The large PV cell-emitter separation distance allows for the design of efficient cooling systems for the PV cell. Furthermore, the STPV design presented in this work is expected to be less expensive and more durable than competing STPV systems because it comprises simple robust components that can withstand high temperatures. All of these advantages are achieved without using selective emitters, optical fibers or

(a)

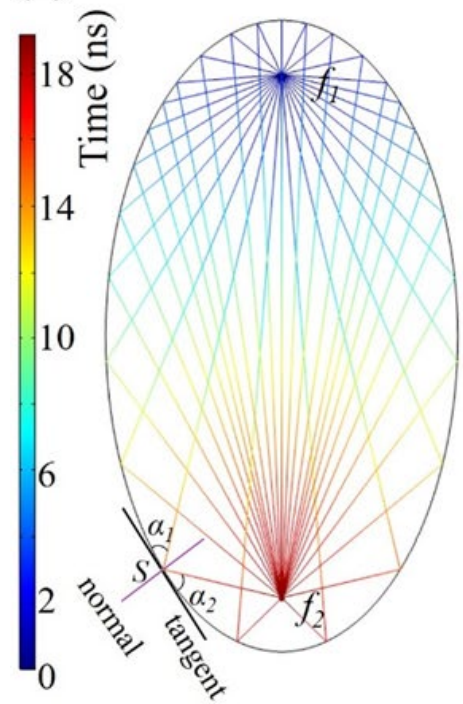

(b) Concentrated solar

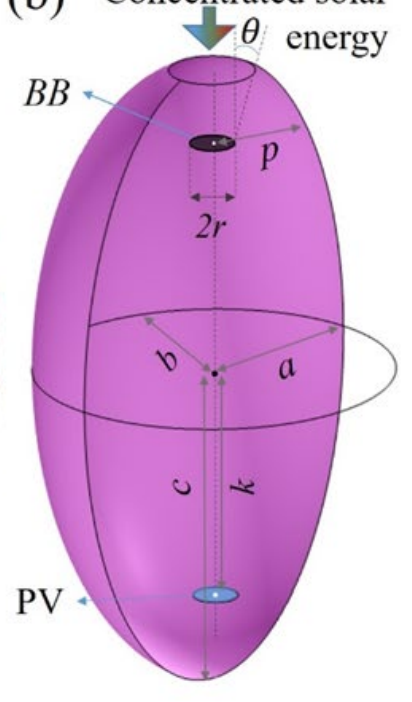

composite, structured or multilayer materials which increase system costs and can decrease durability at high operating temperatures. Also, low-bandgap PV cells are the most expensive component in STPV systems, and the ellipsoidal cavities proposed in this study enable cost reductions because high conversion efficiencies can be achieved using small PV cell areas. Moreover, a sealed glass window can be placed at the entrance port of the RESC structures, which can then be operated under vacuum conditions to minimize convective and conductive heat losses. Another important advantage of the RESC structure is that it enables a low emitter-to-absorber area ratio of $A_{e m t} / A_{a b s}=2$. In comparison, for planar STPV systems a large emitter-to-absorber area ratio $(\sim 5$ to 30 times $)$ is typically used to achieve reasonable efficiencies.

The structure of this paper is as follows: in Section Three the methods used to determine the probable fates of photons radiated form the emitter, and to evaluate the performance of STPV systems, are presented. Specifically, numerical methods used to determine the output power, system efficiency, effective emissivity, and heat load on the PV cell for STPV systems are described in detail. The results and discussions are presented in Section Four. Section 4a describes the effects of the geometrical parameters of the RESC structure on the fate of emitted photons. The ability to control the degree of photon recycling through the design of the RESC structure is also covered in Section 4a. The performance parameters for different RESCbased STPV systems, including the output power density and system efficiency, are compared in Section $4 \mathrm{~b}$. In Section $4 \mathrm{c}$ the heat load and cooling requirements for keeping the PV cell at room temperature are discussed. Finally, conclusions and future works are provided in Section Five.

\section{METHOD}

Comsol Multiphysics and MATLAB software are used for ray optics analysis and numerical computation, respectively, to

(c)

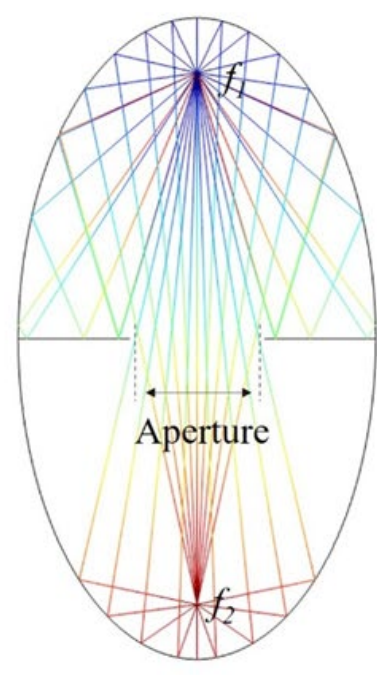

(d)

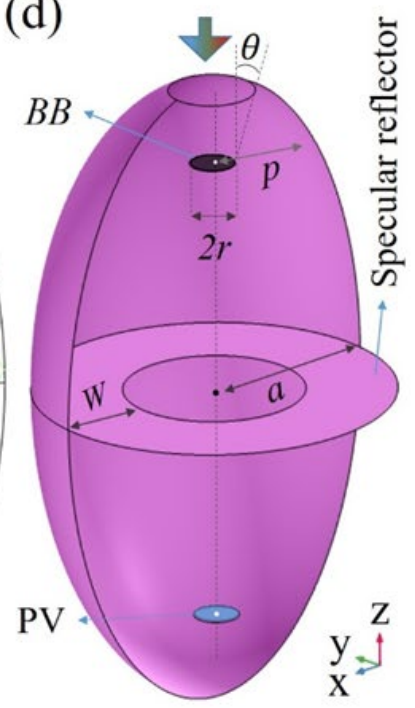

Fig. 1. (a) Schematic of an ellipse showing the optical refocusing of light emitted from $f_{1}$ onto $f_{2}$. (b) Prolate spheroid used as an optical cavity to convert

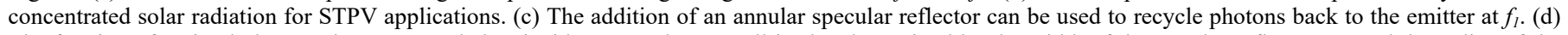

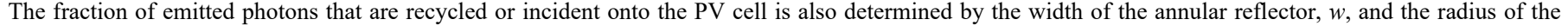
aperture, $a-w$, respectively. 
determine the probable fate of photons emitted from the BB shown in Fig. 1. Four different fates are considered; photons are either absorbed by the PV cell ( $F_{P V}$ - effective view factor), returned to and absorbed by the $\mathrm{BB}$ emitter (i.e. photon recycling, $\left.F_{B B}\right)$, lost through the top entrance port $\left(F_{e s c}\right)$, or absorbed by the cavity walls $\left(F_{c a v}\right)$. The photon fate probabilities are used to calculate the effective emissivity, $\varepsilon^{*}$, for the emitter within the RESC structures shown in Fig. 1. The effective emissivity is the emittance an emitter would have in the absence of a cavity that results in equivalent radiative losses as compared to the case when the cavity is present $[42,43]$. The higher the photon recycling, the lower the effective emissivity. Once the photon fate probabilities and $\varepsilon^{*}$ are known, the power density and efficiency of the RESC-based TPV systems can be calculated. Ray tracing methods are performed to determine the dependency of the emitted photon fate and $\varepsilon^{*}$ on the geometrical parameters of the RESC structures. The following assumptions are made: a) All thermal emission from the BB is assumed to be diffusive and Lambertian. A total number of one million rays are emitted with a Lambertian profile, distributed in a hexapolar grid. b) Unless stated otherwise, $95 \%$ of the light incident onto the internal surface of the RESC structures is reflected and $5 \%$ is absorbed (similar to the reflectivity of Aluminum in the IR spectrum). c) All light rays reflected back to the BB emitter are absorbed. d) Unless stated otherwise, the acceptance angle, $\theta$, is constant at $5^{\circ}$, which allows for a maximum solar concentration of $\sim 350 \mathrm{X}$. e) The cavity is at a pressure of $10 \mathrm{mTorr}(\sim 1.3 \mathrm{~Pa})$ or less [44]. $\mathrm{f})$ The PV cell is assumed to be sufficiently cooled such that its temperature is maintained at $300 \mathrm{~K}$ (the heat load and cooling power required to keep the PV at $300 \mathrm{~K}$ are calculated). g) All radiation incident onto the PV cell is absorbed $\left(\varepsilon_{\text {cell }}=1\right)$, and the External Quantum Efficiency of a GaSb PV cell ( $\left.\mathrm{EQE}_{\mathrm{GaSb}}\right)$ is used to calculate the electrical power generated [45]. The mesh sizes are normalized to the radius of the emitter. The nondimensional mesh size does not exceed 0.01 , and the maximum relative tolerance for convergence is $10^{-5}$. According to the design parameters considered in this study, all photons absorbed by the PV cell come from the emitter, and photons from the sun are not directly incident onto the PV cell.

As noted previously, the emitter can be made from graphite, which has a high thermal conductivity. Furthermore, the ratio of the surface area of the emitter to that of the absorber is low $\left(A_{\text {emt }} / A_{a b s}=2\right)$ in comparison to that in other TPV systems. Moreover, the thickness of this disc-shaped emitter can be made to be small such that the thermal resistance through the emitter is low. Under these circumstances a constant temperature distribution on the emitter surface can be assumed [46]. Additionally, the performance degradation of a $\mathrm{GaSb}$ cell under non-uniform illumination due to temperature gradients on the emitter within a TPV system has been investigated [2]. In this study, the temperature of a blackbody emitter was assumed to vary from $1510 \mathrm{~K}$ to $1990 \mathrm{~K}$. Results from this study estimated that the temperature gradients on the emitter caused a decrease in the PV cell efficiency of only $1.5 \%$ (which corresponded to a $4.4 \%$ relative decrease in efficiency). [17].

The directional emittance, $\varepsilon$, can be integrated across the surface of the emitter to determine the effective emissivity as shown in (1) [43]:

$$
\varepsilon^{*}=\frac{2}{A_{e m t}} \int_{A_{e m t}} \int_{0}^{\pi / 2} \varepsilon^{\prime}(\phi, x, y) \cos \phi \sin \phi d \phi d A
$$

where, $A_{e m t}$ is the area of the emitter surface and $\phi$ is the polar angle. When using ray tracing methods, it is convenient to express the effective emissivity using (2) [42]:

$$
\varepsilon^{*}=\varepsilon_{e m t}\left(1-\frac{N_{a b s}}{N_{t o t}}\right)
$$

where, $N_{t o t}$ and $N_{a b s}$ are the total number of rays emitted and reabsorbed by the $\mathrm{BB}$, respectively and $\varepsilon_{e m t}$ is the emissivity of the BB absorber/emitter $\left(\varepsilon_{e m t}=1\right)$. The temperature of the emitter located in an optical cavity, $T^{*}$, can be expressed as a function of $\varepsilon^{*}$ as shown in (3):

$$
T^{*^{4}}=\frac{A_{a b s} \cdot G \cdot C}{A_{e m t} \cdot \sigma \cdot \varepsilon^{*}}+T_{0}^{4}
$$

where, $T_{0}=300 \mathrm{~K}$ is the initial temperature of the optical cavity and PV cell, $\sigma$ is the Stefan-Boltzmann constant, $G$ is the direct solar irradiance, $C$ is the solar concentration factor, $A_{a b s}$ is the $\mathrm{BB}$ absorber area, and $A_{\text {emt }}$ is the $\mathrm{BB}$ emission area. In this study $A_{\text {emt }}=2 \cdot A_{\text {abs }}$ because only the top side of the BB shown in Fig. $1 \mathrm{~b}$ functions as an absorber while both sides of the BB emit thermal radiation. Herein it is assumed that $G=800 \mathrm{~W} / \mathrm{m}^{2}$. Furthermore, the contribution from the $T_{0}$ term in Eq. 3 is less than $0.05 \%$ of $T^{*}$, and is omitted from the calculations in this work. The power and efficiency of the RESC-based TPV systems shown in Fig. 1 are determined by performing an energy balance using the probable fate of emitted photons as shown in (4) and (5):

$$
\begin{gathered}
G \cdot C \cdot A_{a b s}=P_{P V-i n}+P_{c a v .}+P_{e s c .}=A_{e m t} \cdot \varepsilon^{*} \cdot \sigma \cdot T^{* 4} \\
F_{P V}+F_{c a v .}+F_{e s c .}+F_{B B}=1
\end{gathered}
$$

where, $P_{P V-i n}$ is the power received by the PV cell, $P_{c a v}$ is the radiant power absorbed by the optical cavity, and $P_{\text {esc }}$ is the radiant power that escapes the cavity through the entrance port. The efficiency $\left(\eta_{T P V}\right)$ and output electric power for the STPV systems $\left(P_{P V-o u t}\right)$ are calculated using (6) through (12) [47], [48]:

$$
\begin{gathered}
\eta_{T P V}=\frac{P_{P V-\text { out }}}{P_{\text {in }}} \times 100 \% \\
P_{P V-\text { out }}=V_{O C} \times J_{S C} \times F F \\
J_{S C}=F_{P V} \times q \times \int_{0}^{\infty} \frac{\lambda}{h c} \times E\left(\lambda, T^{*}\right) \times E Q E(\lambda) d \lambda
\end{gathered}
$$




$$
\begin{gathered}
E\left(\lambda, T^{*}\right)=\frac{2 \pi h c^{2}}{\lambda^{5}\left[\exp \left(\frac{h c}{\lambda k_{0} T^{*}}\right)-1\right]} \\
V_{O C}=\frac{k_{0} T_{0}}{q} \ln \left(\frac{J_{S C}}{J_{S}}+1\right) \\
F F=\left(1.84 \times 10^{-3}\right) \times T_{0}^{3} \times \exp \left(\frac{-E_{g}}{k_{0} \times T_{0}}\right) \quad\left(\mathrm{amps} / \mathrm{cm}^{2}\right) \\
\left.1-\frac{1}{\ln \left(\frac{J_{S C}}{J_{S}}\right)}\right) \times\left(\begin{array}{c}
\ln \left(\ln \frac{J_{S C}}{J_{S}}\right) \\
\ln \left(\frac{J_{S C}}{J_{S}}\right)
\end{array}\right)
\end{gathered}
$$

where, $V_{O C}$ is the open-circuit voltage of the PV cell, $J_{S C}$ is the short-circuit current density of the PV cell, $F F$ is the fill factor for the PV cell, $q$ is the elementary charge, $E\left(\lambda, T^{*}\right)$ is the spectral emissive power of the $\mathrm{BB}, E Q E(\lambda)$ is the external quantum efficiency of a GaSb PV cell, $h$ is Planck's constant, $c$ is the speed of light, $k_{0}$ is the Boltzmann constant, $T^{*}$ is the equilibrium temperature of the $\mathrm{BB}, T_{0}$ is the temperature of the $\mathrm{PV}$ cell, $J_{S}$ is the saturation current density and $E_{g}$ is the energy bandgap of PV cells. As the spectral emissive power of the BB is changed for different levels of photon recycling, (13) is used to calculate the PV cell efficiency in different system design parameters and structures. Equation (14) is used to calculate the fraction of in-band photons according to the energy bandgap of the GaSb PV cell. The bandgap of the GaSb PV cell is assumed to be $\lambda_{g}=1.72 \mathrm{~nm}$.

$$
\eta_{P V}=\frac{P_{P V-\text { out }}}{P_{P V-\text { in }}} \times 100 \%
$$

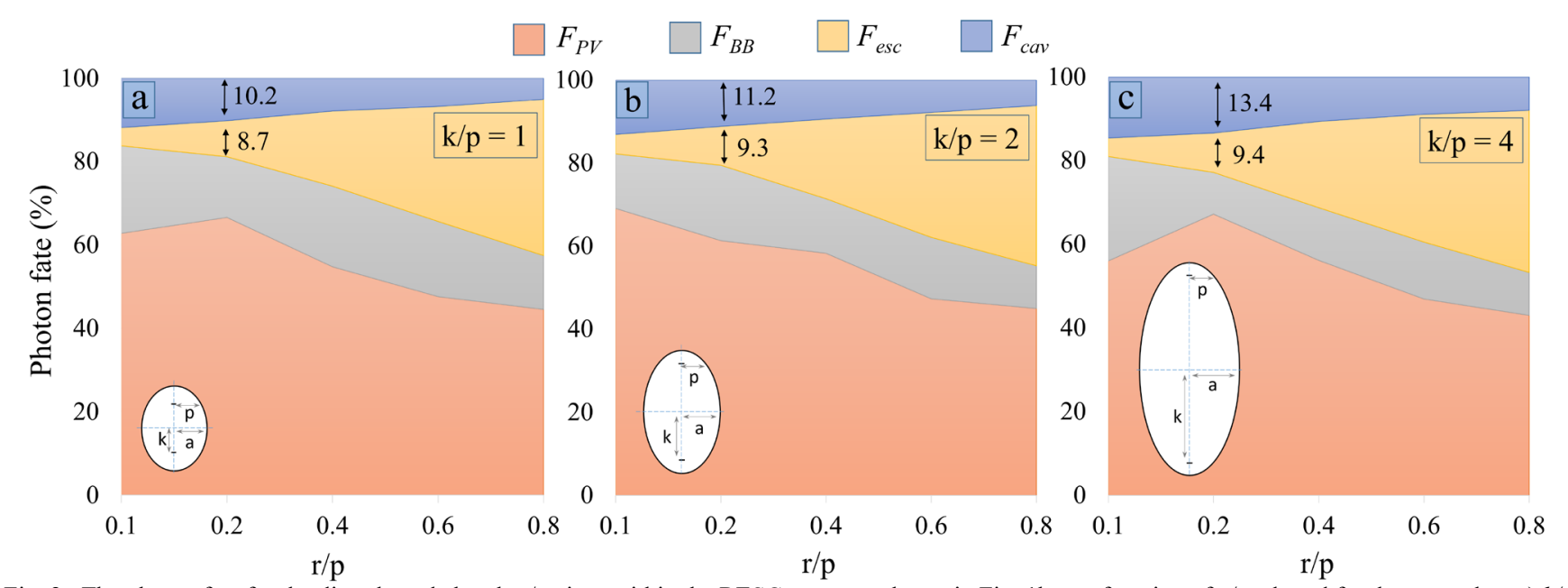

Fig. 2. The photon fate for the disc-shaped absorber/emitter within the RESC structure shown in Fig. $1 \mathrm{~b}$ as a function of $r / p$, plotted for the case when a) $k / p$

Fig. 2. The photon fate for the disc-shaped absorber/emitter within the RESC structure shown in Fig. $1 \mathrm{~b}$
$=1$, b) $k / p=2$, and c) $k / p=4$. The relative lengths of $k$ and $p$ are shown in the inset for each sub-figure.

$$
\eta_{\text {inband }}=\frac{\int_{0}^{\lambda_{g}} E\left(\lambda, T^{*}\right) d \lambda}{\int_{0}^{\infty} E\left(\lambda, T^{*}\right) d \lambda} \times 100 \%
$$

The maximum heat load on the PV cell ( $\left.P_{\text {heat-load }}\right)$ including all heat transfer mechanisms in the system is calculated by (15):

$$
P_{\text {heat-load }}=P_{P V-\text {-in }}-P_{P V-\text { out }}+P_{\text {heat }- \text { cav }}+P_{\text {heat }-B B}
$$

where, the first two terms $\left(P_{P V-\text { in }}-P_{P V-o u t}\right)$ represents the heat generated from radiation absorbed in the PV cell, $P_{\text {heat-cav }}$ is the conductive and radiative heat transferred from the optical cavity to the PV cell (it is assumed the cavity absorbs $5 \%$ of the radiation incident onto its surface which elevates its temperature), and $P_{\text {heat }-B B}$ is the convective and conductive heat transferred from the $\mathrm{BB}$ emitter to the PV cell. The cooling power required to keep the PV cell at $300 \mathrm{~K}$ is assumed to be equal to $P_{\text {heat-load }}$ as given in (15) (for simplicity it is assumed the cooling process is $100 \%$ efficient). In this study the operating pressure of the STPV system is assumed to vary from 0.01 to $1 \mathrm{~Pa}$. The thermal conductivity of air at reduced pressures, $k_{e}$, used to determine $P_{\text {heat-BB }}$ is given by (16) [49]:

$$
k_{e}=\frac{k_{c}}{1+7.657 \times 10^{-5} \times\left(\frac{T_{\text {avg }}}{p \cdot d}\right)}
$$

where, $k_{c}$ is the thermal conductivity of air at atmospheric pressure, $T_{\text {avg }}$ is the average temperature between the emitter and PV cell, $P$ is the reduced pressure in units of Pascals, and $d$ is the distance between the emitter and PV cell. It is assumed convective heat transfer is suppressed at the low operating pressures considered and its effects are neglected [49], [50]. Moreover, the convective heat transfer coefficient between the outer shell of the ellipsoidal cavity and the surrounding environment is set to $h_{c}=10 \mathrm{~W} / \mathrm{m}^{2} \cdot \mathrm{K}$. Simulations are carried out for different separation distances between the emitter and the PV cell (e.g. different values of $k$ with reference to Fig. 1). 
Further, simulations are carried out for the cases wherein the cavity is present and absent, and the results are compared.

\section{RESUlTS AND Discussion}

\section{A. Effects of the geometrical parameters of the RESC} structures on the fate of emitted Photons

\section{1) Effects of the shape of the ellipsoidal cavity on the fate of emitted photons}

Fig. 2 shows the probable fate of photons emitted from the BB located at the focal point of a prolate spheroid (Fig. 1 (a) and (b)) as a function of the ratio between the emitter radius and the semi-latus rectum $(r / p)$ for $k / p=1,2$, and 4 . For the results in Fig. 2 it is assumed the radius of the BB emitter is equal to the radius of the $\mathrm{PV}$ cell $\left(r_{B B}=r_{p v}=r\right)$. If the $\mathrm{BB}$ emitter and $\mathrm{PV}$ cell were point sources, photon recycling, wherein emitted photons are returned to the $\mathrm{BB}$, would not occur. However, due to the finite size of the $\mathrm{BB}$, there is some degree of photon recycling for all cases shown in Fig. 2. As the radius of the BB emitter increases the entrance port increases, causing the escape losses to increase, and the fraction of photons incident onto the PV cell generally decreases. The cavity losses decrease as $r / p$ increases because a larger number of photons emitted from the $\mathrm{BB}$ are directly incident onto the PV cell or escaped through the opening, and less photons are reflected from cavity walls. When $r / p$ is small the escape losses, $F_{e s c}$, is small and the number of rays available to be recycled or delivered to the $\mathrm{PV}$ cell is high, and it is probable to have maximum values for either $F_{p v}$ or $F_{B B}$. As shown in Fig. 2, when $k / p=1$ and $k / p=4, F_{p v}$ has a maximum value at $r / p=0.2$. When $k / p=2, F_{B B}$ has a maximum value at $r / p=0.2$.

In progressing from Fig. $2 \mathrm{a}$ to $2 \mathrm{c}$, as $k / p$ increases from 1 to 4 (for a constant value of $r / p$ ), $F_{c a v}$ increases because the fraction of photons emitted from the BB that are directly incident onto the PV cell (without being reflected from the cavity walls) decreases. For example, when $r / p=0.2, F_{c a v}$ increases from $10.2 \%$ at $k / p=1$ to $11.2 \%$ at $k / p=2$, and to $13.4 \%$ at $k / p=4$. Further, as $k / p$ increases the distance between the BB emitter and the entrance port decreases, which causes $F_{e s c}$ to increase. For example, when $r / p=0.2, F_{\text {esc }}$ increases from $8.7 \%$ at $k / p=1$ to $9.3 \%$ at $\mathrm{k} / \mathrm{p}=2$, and to $9.4 \%$ at $k / p=4$. Therefore, when $k / p$ increases, total losses $\left(F_{c a v}+F_{\text {esc }}\right)$ increase as well, and the efficiency of the system is expected to decrease with increasing values of $k / p$.

2) Controlling the degree of photon recycling by tuning the ratio between the areas of the emitter and $P V$ cells

The trade-off between the percentage of emitted photons that are either recycled or incident onto the $\mathrm{PV}$ cell can be controlled by tuning the ratio between the areas of the PV cell and $\mathrm{BB}$ emitter. The photon fate probabilities for the cases when $r_{p v} / r_{B B}$ $=1, r_{p v} / r_{B B}=0.5$ and $r_{p v} / r_{B B}=2$ are shown in Fig. 3. Results are shown for $k / p=1, k / p=2$, and $k / p=4$, and $r_{B B} / p=0.1$ for all cases. As $r_{p v} / r_{B B}$ increases the fraction of photons incident onto the PV cell (effective view factor) increases. This will increase the output power from the PV cell if these are in-band photons.
However, if the BB temperature is low, and it emits a high percentage of out-of-band photons, the output power from the TPV system can be increased by increasing the degree of photon recycling and therefore the temperature of the $\mathrm{BB}\left(T^{*}\right)$. As shown in the top row of Fig. 3, more than $50 \%$ of the photons emitted from the $\mathrm{BB}$ can be recycled when $r_{p v} / r_{B B}=0.5$. A lower number of photons are incident onto the PV cell when $r_{p v} / r_{B B}=$ 0.5 , however, a greater fraction of these photons are in-band photons due to the increased temperature of the $\mathrm{BB}\left(T^{*}\right)$ and decreased effective emissivity. The net result can be an increase in electric power output. The optimal amount of photon recycling and effective view factor depends on the temperature of the $\mathrm{BB}$ and the EQE of the type of PV cell used.

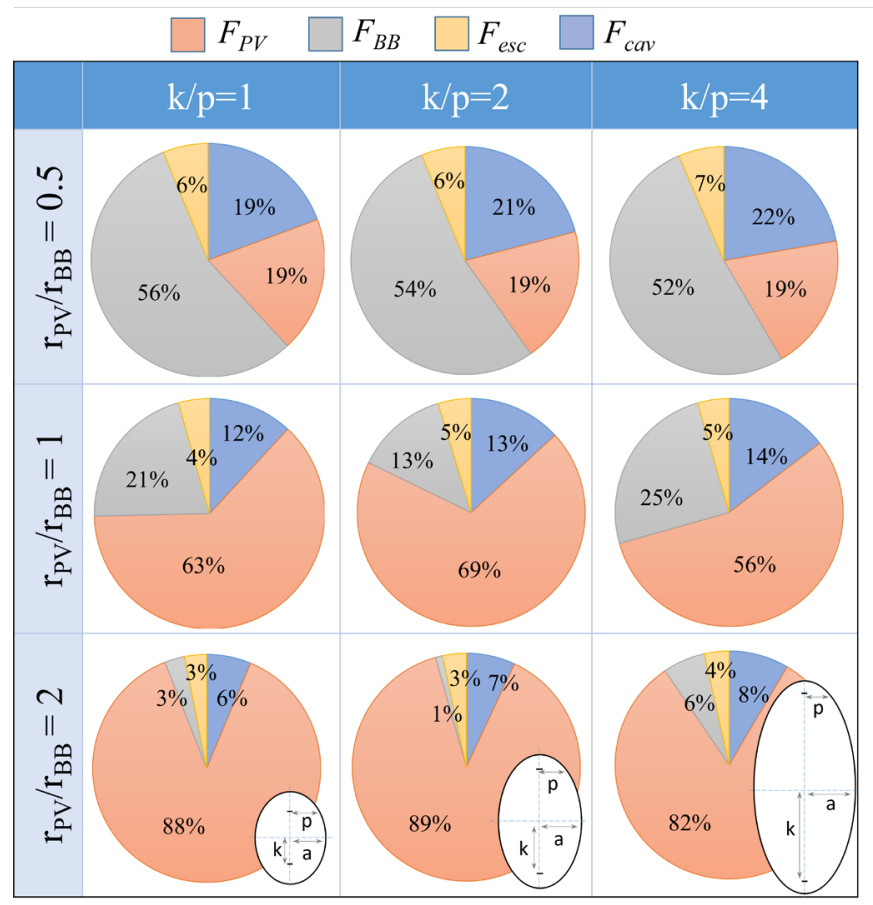

Fig. 3. The photon fate for the disc-shaped emitter within the RESC structure shown in Fig. $1 \mathrm{~b}$ for three different values of $r_{p v} / r_{B B}=0.5,1$ and 2, plotted for the cases when $k / p=1,2$, and 4 . The relative lengths of $k$ and $p$ are shown in the insets.

\section{3) Controlling the degree of photon recycling by adding an} annular reflector at the midplane of the ellipsoidal cavity

In some situations, such as partial overcast conditions, the temperature of the emitter within the RESC structure may be low, and a higher degree of photon recycling can be used to boost its temperature. To achieve a high degree of photon recycling an annular specular reflector can be placed at the midplane of the RESC structure. As shown in Fig. 1c, due to the symmetry of the ellipsoidal cavity, rays emitted from the focal point at $f_{1}$ that are incident onto the annular reflector will be returned to $f_{1}$. The relative width of the annular specular reflector, w/a, can be designed to control the degree of photon recycling (Fig. 1d).

The probable fate of photons emitted from the BB within the RESC structure shown in Fig. 1d are plotted in Fig. 4 as a 


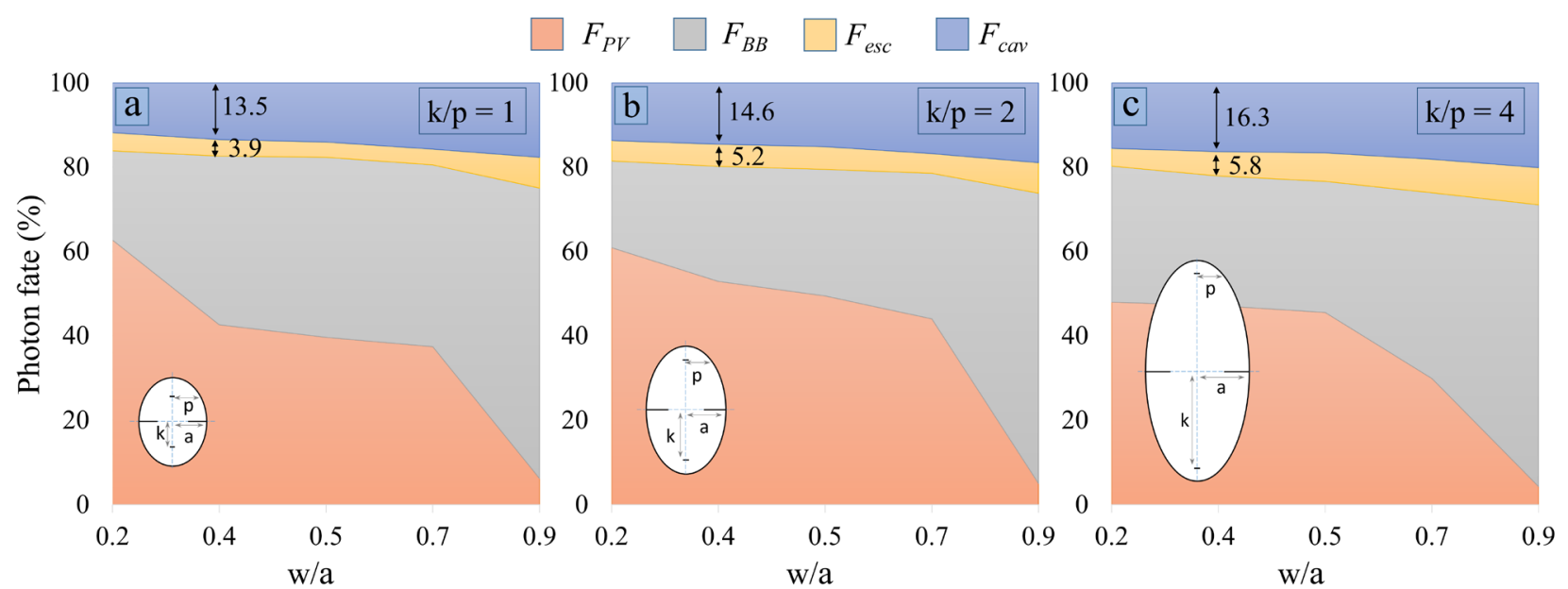

Fig. 4. The photon fate for the disc-shaped emitter within the RESC structure shown in Fig. $1 \mathrm{~d}$ as a function of $w / a$, plotted for the case when a) $k / p=1, \mathrm{~b}$ ) $k / p=2$, and c) $k / p=4$. The relative lengths of $k$ and $p$ are shown in the inset for each sub-figure.

TABLE I

COMPARISON OF THE PERFORMANCE OF SELECTED RESC-BASED STPV SYSTEMS AT A SOLAR CONCENTRATION FACTOR OF C $=350 \mathrm{X}$.

\begin{tabular}{|c|c|c|c|c|c|c|c|c|}
\hline & TPV system & $\varepsilon^{*}$ & Temp. (K) & $\begin{array}{c}\text { Effective } \\
\text { view factor } \\
\left(F_{P V} \%\right)\end{array}$ & $\begin{array}{l}\text { In-band photon } \\
\left(\eta_{\text {inband }} \%\right)\end{array}$ & $\begin{array}{l}\text { PV output } \\
\text { power density } \\
\left(\mathrm{W} / \mathrm{cm}^{2}\right)\end{array}$ & $\begin{array}{c}\text { PV cell } \\
\text { efficiency } \\
\left(\eta_{P V} \%\right)\end{array}$ & $\begin{array}{c}\text { System } \\
\text { efficiency } \\
\left(\eta_{T P V} \%\right)\end{array}$ \\
\hline \multicolumn{2}{|c|}{$\begin{array}{l}\text { No cavity-ideal case (two parallel infinite } \\
\text { plates) }\end{array}$} & 1 & 1253.5 & 50 & 9.33 & 0.67 & 4.76 & 2.38 \\
\hline \multirow{3}{*}{$\begin{array}{l}\text { Prolate } \\
\text { spheroid }\end{array}$} & $\begin{array}{l}\mathrm{PS}_{1} \quad \mathrm{r}_{\mathrm{PV}} / \mathrm{r}_{\mathrm{BB}}=0.5, \mathrm{k} / \mathrm{p}=1 \\
\mathrm{r}_{\mathrm{BB}} / \mathrm{p}=0.1\end{array}$ & 0.442 & 1537.4 & 18.8 & 19.4 & 2.3 & 9.5 & 4.05 \\
\hline & $\mathrm{PS}_{2} \quad \mathrm{r}_{\mathrm{PV}} / \mathrm{r}_{\mathrm{BB}}=2, \mathrm{k} / \mathrm{p}=2, \mathrm{r}_{\mathrm{BB}} / \mathrm{p}=0.1$ & 0.99 & 1256.7 & 88.7 & 9.43 & 0.155 & 4.9 & 4.42 \\
\hline & $\mathrm{PS}_{3} \quad \mathrm{r}_{\mathrm{PV}} / \mathrm{r}_{\mathrm{BB}}=1, \mathrm{k} / \mathrm{p}=1, \mathrm{r}_{\mathrm{BB}} / \mathrm{p}=0.1$ & 0.79 & 1329.6 & 62.77 & 11.8 & 0.68 & 6.1 & 4.85 \\
\hline \multirow{3}{*}{$\begin{array}{l}\text { Prolate } \\
\text { spheroid } \\
\text { with } \\
\text { annular } \\
\text { specular } \\
\text { reflector }\end{array}$} & $\begin{array}{l}\mathrm{PSA}_{1} \mathrm{r}_{\mathrm{pv}} / \mathrm{r}_{\mathrm{BB}}=1, \mathrm{k} / \mathrm{p}=1 \\
\mathrm{r}_{\mathrm{BB}} / \mathrm{p}=0.1, \mathrm{w} / \mathrm{a}=0.5\end{array}$ & 0.573 & 1440.8 & 39.6 & 15.7 & 0.775 & 8 & 5.53 \\
\hline & $\begin{array}{l}\mathrm{PSA}_{2} \mathrm{r}_{\mathrm{pv}} / \mathrm{r}_{\mathrm{BB}}=2, \mathrm{k} / \mathrm{p}=1 \\
\mathrm{r}_{\mathrm{BB}} / \mathrm{p}=0.1, \mathrm{w} / \mathrm{a}=0.7\end{array}$ & 0.67 & 1385 & 53.43 & 13.72 & 0.197 & 7.1 & 5.62 \\
\hline & $\begin{array}{l}\mathrm{PSA}_{3} \mathrm{r}_{\mathrm{pv}} / \mathrm{r}_{\mathrm{BB}}=2, \mathrm{k} / \mathrm{p}=2 \\
\mathrm{r}_{\mathrm{BB}} / \mathrm{p}=0.1, \mathrm{w} / \mathrm{a}=0.9\end{array}$ & 0.306 & 1685.4 & 5.5 & 25.1 & 0.074 & 11.7 & 2.1 \\
\hline
\end{tabular}

function of $w / a$ for the cases wherein $k / p=1, k / p=2$, and $k / p=$ 4 , and $r / p$ is kept constant at $0.1\left(r_{p v}=r_{B B}=r\right)$. The specular reflectivity and absorptivity of the annular reflector are assumed to be $95 \%$ and $5 \%$, respectively. Losses due to absorption by the annular reflector are included in the cavity losses, which increase slightly as $w / a$ increases.

As shown in Fig. 4, as $w / a$ increases the degree of photon recycling increases while the fraction of emitted photons incident onto the PV cell (effective view factor) decreases. These trends illustrate the trade-off between $F_{B B}$ and $F_{P V}$. Increasing the degree of photon recycling (by increasing $F_{B B}$ ) increases the temperature of the emitter and the number of inband photons it emits. However, increasing the degree of photon recycling also decreases the fraction of photons incident onto the PV cell. The value of $w / a$ can be tuned to optimize the number of in-band photons incident onto the PV cell. For the cases considered in Fig. 4, a maximum photon recycling value of $68.8 \%\left(\varepsilon^{*}=0.312\right)$ is achieved when $k / p=1$ and $w / a=0.9$.

In progressing from Fig. $4 \mathrm{a}$ to $4 \mathrm{c}$, as $k / p$ increases from 1 to 4 (for a constant value of $w / a$ ), $F_{c a v}$ increases because the distance between the emitter and the aperture at the center of the annular ring increases. A lower percentage of emitted photons pass through the aperture as its distance from the PV cell increases. On the other hand, the field of view between the emitter and the cavity walls (including the annular reflector) increases as the emitter-aperture distance increases, which results in an increase in the average number of reflection events and $F_{c a v}$. For example, when $w / a=0.4, F_{c a v}$ increases from $13.5 \%$ at $k / p=1$ to $14.6 \%$ at $\mathrm{k} / \mathrm{p}=2$, and to $16.3 \%$ at $k / p=4$. Further, as $k / p$ increases the distance between the BB emitter and the entrance port decreases, which causes $F_{\text {esc }}$ to increase. For example, when $w / a=0.4, F_{\text {esc }}$ increases from $3.9 \%$ at $k / p=$ 1 to $5.8 \%$ at $k / p=4$. Therefore, when $k / p$ increases, the total losses $\left(F_{c a v}+F_{e s c}\right)$ increase, and this will generally cause a decrease in system efficiency.

\section{B. Performance comparisons of RESC-based STPV systems}

The performance of selected RESC-based STPV systems is compared to that of a hypothetical reference case comprised of a BB emitter and a GaSb PV cell configured as two infinite parallel plates in Table 1. This hypothetical reference case is referred to as the "no cavity-ideal case" in the first row of Table 1. Considering there is not cavity present for this this ideal case, the photon fates used to calculate the results shown in Table 1 are: $F_{P V}=50 \%, F_{B B}=0 \%, F_{e s c}=50 \%$, and $F_{c a v}=0 \%$. For all 


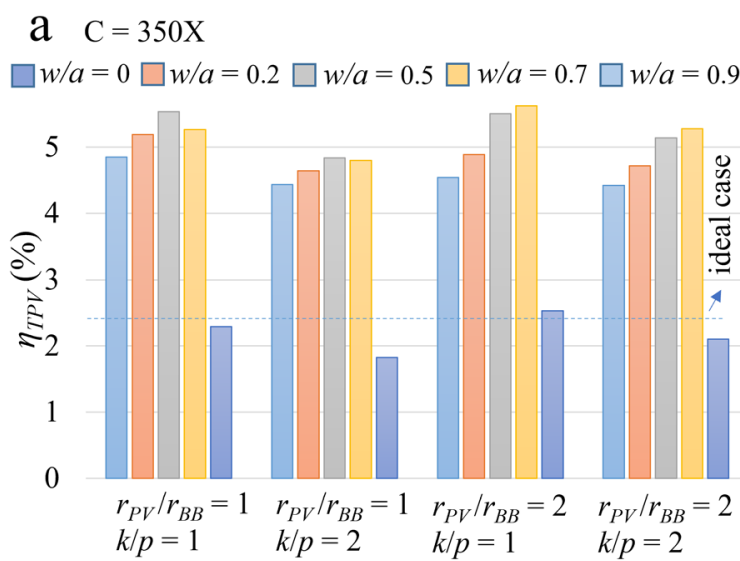

C $\mathrm{C}=1400 \mathrm{X}$

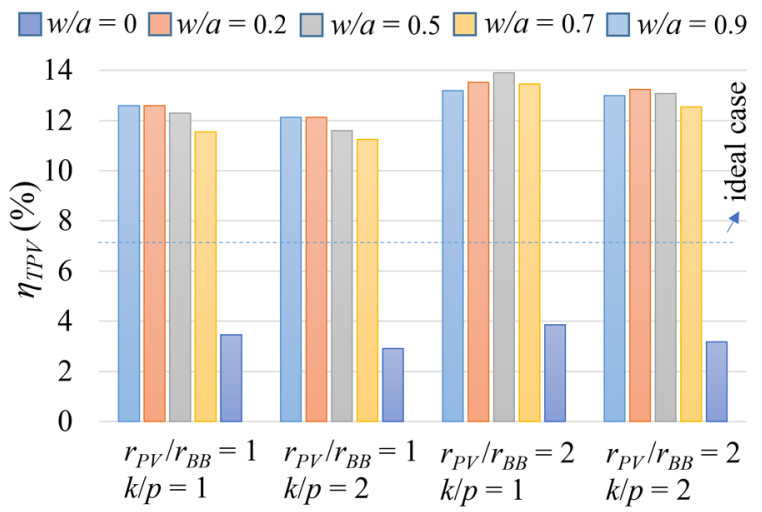

b $\mathrm{C}=700 \mathrm{X}$

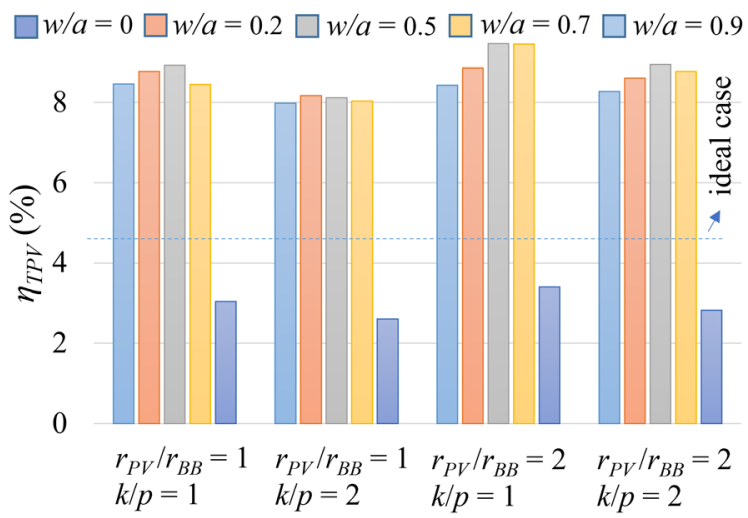

d

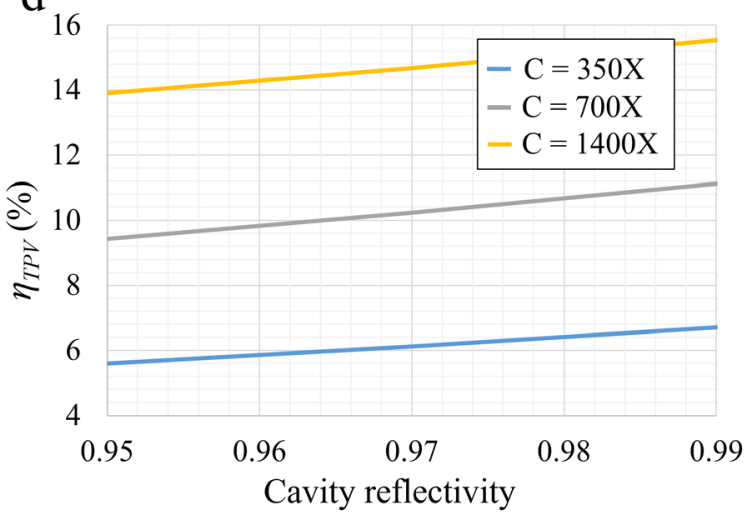

Fig. 5. System efficiency for various RESC-based STPV configurations with different combinations of values for $w / a(0,0.2,0.5,0.7,0.9), r_{p v} / r_{b b}$ and $k / p$, for the cases wherein the solar concentration factor is a) 350X, b) 700X, c) 1400X, and d) System efficiency for the best cases shown in Figs. 5a through 5c for solar concentration factors of 350X, 700X, and 1400X plotted as a function of the specular reflectivity of the ellipsoidal optical cavity for values ranging from $95 \%$ to $99 \%$.

cases in Table 1 the solar intensity incident onto the BB emitter is $28 \mathrm{~W} / \mathrm{cm}^{2}\left(G \cdot C=800 \mathrm{~W} / \mathrm{m}^{2} \cdot 350=28 \mathrm{~W} / \mathrm{cm}^{2}\right)$. For the reference STPV system (ideal case), the temperature of the emitter reaches $1253.5 \mathrm{~K}$ and $50 \%$ of the solar energy concentrated onto the STPV system is ultimately radiated from the emitter onto the PV cell and the other half is lost through the top surface of the BB. However, only $9.33 \%$ of the photons emitted are in-band $\left(\eta_{\text {inband }}\right)$ and the system efficiency for the ideal reference case is $2.38 \%$. The efficiency of the PV cell in this case is $4.76 \%$. The performance of the STPV system can be improved by using the prolate-spheroid cavity shown in Fig. 1b. As shown in Table 1, the effective emissivity of the BB can be reduced to 0.442 for the case when $r_{p v} / r_{B B}=0.5, k / p=1$, and $r_{B B} / p=0.1$; the BB temperature increases to $1537.37 \mathrm{~K}, 19.4 \%$ of the emitted photons are in-band, and the system efficiency, output power density and PV cell efficiency are 4.05\%, 2.3 $\mathrm{W} / \mathrm{cm}^{2}$ and $9.5 \%$, respectively. The efficiency increases to $4.42 \%$ for the case when $r_{p v} / r_{B B}=2, k / p=2$, and $r_{B B} / p=0.1$ because although the in-band photons are $11 \%$, the percentage of photons emitted from the BB that are incident onto the PV cells (effective view factor) increases to $88.7 \%$. The highest efficiency of $4.85 \%$ for the RESC-based TPV system shown in Fig. $1 \mathrm{~b}$ occurs when $r_{p v} / r_{B B}=1, k / p=1$, and $r_{B B} / p=0.1$; this is due to the combination of a relatively high $\mathrm{BB}$ temperature (1329.6 K), low effective emissivity (or a high degree of photon recycling), and a high effective view factor between the emitter and the PV cell $(62.77 \%)$.

The performance of the STPV system can be further improved by including an annular specular reflector at its midplane (Fig. 1d) as shown in the next part of Table 1. Fig. 5 shows the efficiency for various RESC-based STPV configurations with different combinations of values for $w / a(0$, $0.2,0.5,0.7,0.9), r_{p v} / r_{b b}$ and $k / p$, for the cases wherein the solar concentration factor is $350 \mathrm{X}$ (Fig. 5a), $700 \mathrm{X}$ (Fig. 5b), and 1400X (Fig. 5c), where $\theta=5^{\circ}, 7.1^{\circ}$ and $10.1^{\circ}$ for $C=350 \mathrm{X}$, $700 \mathrm{X}$ and 1400X, respectively. The results presented in Figs. $5 \mathrm{a}$ through $5 \mathrm{c}$ were attained assuming the specular reflectivity of the optical cavity is $95 \%$. As shown in Figs. 5a through 5c, for most configurations the system efficiency increases as $w / a$ increases due to enhanced photon recycling which raises the emitter temperature. However, there is an optimal value of $w / a$ because the emitter-to-cell effective view factor decreases as the width of the annular reflector increases.

At a solar concentration factor of $350 \mathrm{X}$ the efficiency of a hypothetical STPV system (ideal case) wherein the emitter and $\mathrm{PV}$ cell are two parallel infinite plates is $2.38 \%$ (shown as the dashed blue line in Fig 5a). As shown in Fig. 5a, for the RESCbased STPV structure operating at a solar concentration factor of $350 \mathrm{X}$ the highest efficiency of $5.62 \%$ is achieved when $r_{p v} / r_{B B}=2, k / p=1, r_{B B} / p=0.1$, and $w / a=0.7$; for this case the effective emissivity, temperature of the $\mathrm{BB}$ and $\mathrm{PV}$ cell efficiency is $0.67,1385 \mathrm{~K}$, and $7.1 \%$, respectively. Notably, the 
lowest effective emissivity, highest BB temperature, in-band photons and PV cell efficiency are $0.306,1685.4 \mathrm{~K}, 25 \%$ and $11.7 \%$, respectively, for the case when $r_{p v} / r_{B B}=2, k / p=2, r_{B B} / p$ $=0.1$, and $w / a=0.9$. However, the efficiency for this case is only $2.1 \%$ because only $5.5 \%$ of the photons emitted from the $\mathrm{BB}$ are incident onto the PV cell. A comprehensive system evaluation of RESC-based STPVs for different design parameters is provided in Table S1 in the Supporting Information for the incoming solar concentration ratio of $350 \mathrm{X}$ and the specular reflectivity of the optical cavity of $95 \%$.

At solar concentration factors of $700 \mathrm{X}$ and 1400X the efficiency of a hypothetical STPV system (ideal case) wherein the emitter and PV cell are two parallel infinite plates is $4.5 \%$ and $7.22 \%$, respectively (shown as the dashed blue lines in Fig $5 \mathrm{~b}$ and $5 \mathrm{c}$ ). As shown in Figs. $5 \mathrm{~b}$ and $5 \mathrm{c}$, the highest efficiencies of $9.4 \%$ and $13.9 \%$ are predicted for RESC-based STPV structures when operating at solar concentration factors of $700 \mathrm{X}$ and $1400 \mathrm{X}$, respectively. Referring to Fig. 5, overall, the RESC structures with $k / p=1$ have higher system efficiencies in comparison to RESC structures with $k / p=2$. The reason is that the total losses $\left(F_{e s c}+F_{c a v}\right)$ for RESC structures with $k / p=1$ is smaller than that of RESC structures with $k / p=2$ as shown in Figs. 2 to 4.

For the best case shown in Figs. 5a through 5c, further improvements are considered by increasing the reflectivity of the optical cavity from $95 \%$ to $99 \%$ (Gold and Silver coatings can achieve $99 \%$ reflectivity in the IR region). As shown in Fig. $5 \mathrm{~d}$, for the best configuration at $C=350 \mathrm{X}$ ( $\mathrm{PSA}_{2}$ in Table 1), when the reflectivity of the optical cavity increases from $95 \%$ to $99 \%$, the system efficiency increases from 5.62 to $6.7 \%$. When the solar concentration factor is $C=700 \mathrm{X}$, the efficiency of the selected STPV system $\left(r_{p v} / r_{B B}=2, k / p=1\right.$, and $\left.w / a=0.5\right)$ increases from 9.4 to $11.1 \%$ as the reflectivity of the optical cavity increases from $95 \%$ to $99 \%$. By further increasing the solar concentration to $C=1400 \mathrm{X}$, the efficiency of the selected STPV system $\left(r_{p v} / r_{B B}=2, k / p=1\right.$, and $\left.w / a=0.5\right)$ increases from $13.9 \%$ at $95 \%$ reflectivity of the optical cavity to $15.4 \%$ at $99 \%$ reflectivity of the optical cavity.

\section{Heat load and cooling power}

Conductive heat losses within a TPV system can be decreased by reducing the operating pressure. In this study, the operating pressure is varied from 0.01 to $1 \mathrm{~Pa}$ to investigate the effect of conductive heat transfer in the proposed TPV systems on the cooling power required to keep the PV cell at $300 \mathrm{~K}$. Considering (15), the heat-load on the PV cell comes from two main sources: 1) $P_{\text {Con-heat }}$ : conductive heat transferred from the ellipsoidal cavity and $\mathrm{BB}$ emitter, and 2) $P_{\text {Radiation-heat }}$ radiative heat transferred from the $\mathrm{BB}$ emitter and the surface-to-surface radiation transferred from the optical cavity to PV cell $\left(P_{c a v-P V}\right)$. These two heat load sources can be derived from (15) as follow:

$$
\begin{gathered}
P_{\text {Con-heat }}=P_{\text {heat-cav }}+P_{\text {heat }-B B} \\
P_{\text {Radiation-heat }}=P_{P V-\text {-in }}-P_{P V-\text { out }}+P_{C a v-P V}
\end{gathered}
$$

However, the heat load induced by the cavity is negligible as the temperature of the cavity increases by a maximum of $3 \mathrm{~K}$ for all cases considered, and the $P_{\text {heat-cav }}$ and $P_{\text {cav }-P V}$ terms in (17) and (18) are neglected.

Herein the heat load on the PV cell is investigated for six different TPV systems at operating pressures ranging from 0.01 to $1 \mathrm{~Pa}$. The first two STPV systems, $\mathrm{PS}_{1}$ and $\mathrm{PS}_{3}$, have the prolate spheroid configuration as shown in Fig. 1b. The next two STPV systems, PSA $_{1}$ and $\mathrm{PSA}_{2}$, have a prolate spheroid configuration with the addition of an annular ring, as shown in Fig. 1d. The geometrical parameters for the $\mathrm{PS}_{1}, \mathrm{PS}_{3}, \mathrm{PSA}_{1}$ and $\mathrm{PSA}_{2}$ TPV configurations are available in Table 1. Further, for the $\mathrm{PS}_{1}, \mathrm{PS}_{3}, \mathrm{PSA}_{1}$ and $\mathrm{PSA}_{2}$ configurations it is assumed the walls of the optical cavity are $0.5 \mathrm{~cm}$ thick and are made from Aluminum. The convective heat transfer coefficient between the outer surface of the cavity and the surrounding environment is $h_{c}=10 \mathrm{~W} / \mathrm{m}^{2} \mathrm{~K}$. For these four cases, $r_{B B}$ is set to $1 \mathrm{~cm}$, which sets $k=10 \mathrm{~cm}$. The final two STPV configurations considered comprise an emitter and PV cell without the presence of an optical cavity (referred to as "non-Cavity"). For these two reference configurations $r_{B B}=r_{P V}=1 \mathrm{~cm}$. Furthermore, the separation distance between the $\mathrm{BB}$ emitter and $\mathrm{PV}$ cell for these two cases is selected to be $2 \cdot k=0.5 \mathrm{~mm}$ and $2 \cdot k=1 \mathrm{~mm}$, such that the efficiency of these systems is comparable to the efficiency of the $\mathrm{PS}_{1}, \mathrm{PS}_{3}, \mathrm{PSA}_{1}$ and $\mathrm{PSA}_{2}$ STPV systems. If the separation distance between the emitter and PV cell were set to be the same as that of the $\mathrm{PS}_{1}, \mathrm{PS}_{3}, \mathrm{PSA}_{1}$ and $\mathrm{PSA}_{2}$ configurations $(2 \cdot k=20 \mathrm{~cm})$ then the system efficiency for these reference cases would be less than $0.005 \%$. To model the heat transfer for the reference cases it is assumed the PV cell is located on an aluminium substrate with a thickness of $0.5 \mathrm{~cm}$. The convection heat transfer coefficient between this substrate and the surrounding environment is $h=10 \mathrm{~W} / \mathrm{m}^{2} \cdot \mathrm{K}$.

Fig. 6 shows the ratio of the heat load on the PV cell to the output power due to conductive heat transfer within the STPV system for the six aforementioned case studies. For all six cases considered the conductive heat load on the PV cell is small in comparison to the output power from the PV cell up to an operating pressure of $10^{-1} \mathrm{~Pa}$. However, as the operating

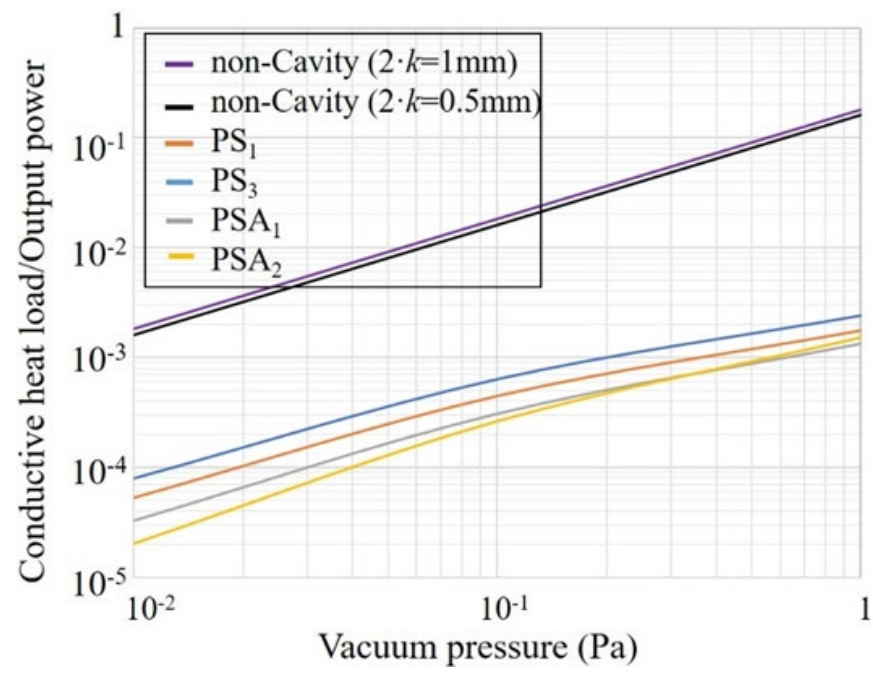

Fig. 6. The ratio of the conductive heat load on the PV cell to the generated power for six case studies plotted over the pressure range from 0.01 to $1 \mathrm{~Pa}$. 
pressure approaches $1 \mathrm{~Pa}$ the heat load on the PV cell due to conductive heat transfer within the reference cases (non-cavity with $2 \cdot k=0.5 \mathrm{~mm}$ and $2 \cdot k=1 \mathrm{~mm}$ ) becomes comparable to the output power from the PV cell. In fact, at $1 \mathrm{~Pa}$ the conductive heat transferred to the PV cell is 16 and $18 \%$ of the output power for the $2 \cdot k=0.5 \mathrm{~mm}$ and $2 \cdot k=1 \mathrm{~mm}$ reference cases, respectively. On the other hand, the conductive heat load transferred to the PV cell for the cases wherein the ellipsoidal optical cavity is present $\left(\mathrm{PS}_{1}, \mathrm{PS}_{3}, \mathrm{PSA}_{1}\right.$ and $\left.\mathrm{PSA}_{2}\right)$ is less than $1 \%$ of the output power from the PV cell for operating pressures up to $1 \mathrm{~Pa}$. Notably, achieving vacuum levels of $1 \mathrm{~Pa}$ is relatively inexpensive, whereas higher vacuum levels require more complex equipment such as multistage rotary vane, diffusion or turbomolecular pumps.

Fig. 7 shows the radiative heat load and output power for PV cells within the six aforementioned STPV configurations. Of the six STPV configurations considered, the radiative heat load on the PV cell for the $\mathrm{PS}_{1}$ configuration is the smallest and, due to its relatively high output power $(3.6 \mathrm{~W})$, the ratio of the radiative heat load to the output power is the smallest (9.5). For the non-cavity structures, the radiation cooling power required

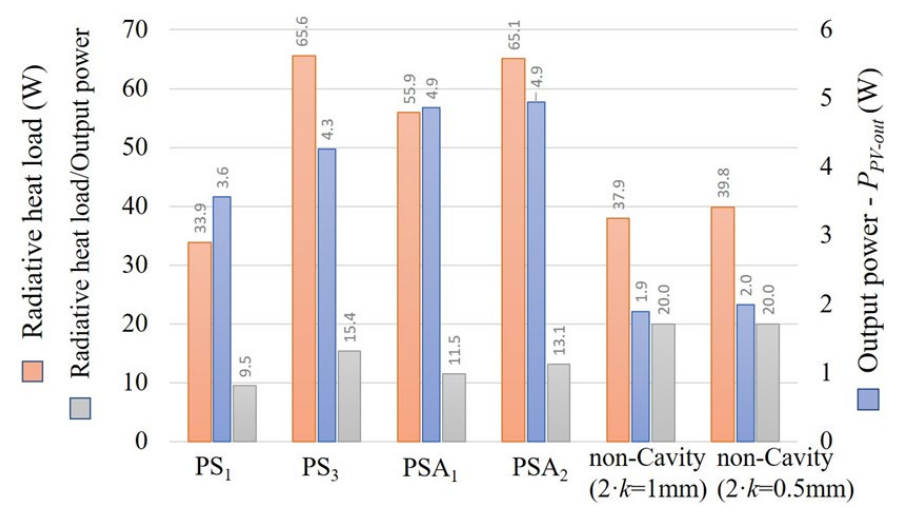

Fig. 7. The results of the radiative heat load/power required to keep the temperature of the PV cell at $300 \mathrm{~K}$ for six case studies.

to keep the PV cell at $300 \mathrm{~K}$ is close to $40 \mathrm{~W}$, the power output generated by the PV cell is $\sim 2 \mathrm{~W}$, and the radiative cooling power to output power ratio is $\sim 20$. Thus, the non-cavity STPV systems requires 20 times the output power generated to be removed as heat to keep the PV cell at $300 \mathrm{~K}$. In comparison, this ratio is 9.5, 15.4, 11.5, and 13.1 for $\mathrm{PS}_{1}, \mathrm{PS}_{3}, \mathrm{PSA}_{1}$ and $\mathrm{PSA}_{3}$, respectively. This heat load can be dissipated by different passive and active techniques.

As shown from Figs. 5 and 6 the dominant heat transfer mechanism to the PV cell is radiative heat transfer. The radiative heat transferred from the emitter to the PV cell depends on the effective view factor and the degree of photon recycling. A high effective view factor is required to achieve high system efficiency, but increases the radiative heat load to the PV cell. A high degree of photon recycling can reduce the radiative heat load on the PV cell by increasing the emitter temperature and reducing the number of incident out-of-band photons (which are assumed to contribute to the heat load on the PV cell in this work). On the other hand, high emitter temperatures also increase the average energy of in-band photons incident onto the PV cell which results in higher thermalization losses, thereby increasing the heat load on the PV cell. It should be noted that using the RESC structure and increasing the separation distance between the PV cell and emitter allows for the PV cell to be brought out of the vacuum enclosure where superior cooling systems that make use of conductive and convective heat transfer can be implemented. Considering future work, selective emitters and filters can be integrated into the design of the RESC-based STPV systems to reduce the amount of out-of-band photons incident onto the PV cell, increase the degree of photon recycling and emitter temperature, and ultimately increase system efficiency. For example, filters that selectively reflect out-of-band photons while transmitting in-band photons can be integrated at the midplane of the ellipsoidal optical cavity or at the upper surface of the PV cell. Further, selective filters that transmit solar radiation while reflecting thermal radiation from the emitter can be placed at the opening at the top of the ellipsoidal optical cavity to further decrease the emission losses through the top opening $\left(F_{\text {esc }}\right)$ [51]-[53]. As mentioned previously, the performance of selective emitters and filters can degrade due to extended exposure to high temperatures. However, the performance of RESC-based STPV systems proposed in this work can be more tolerant to degradation of these components because the optical cavity may be made from durable materials that can continue to provide high emitter-to-cell effective view factors and a high degree of photon recycling despite prolonged exposure to radiant energy from emitters operation at high temperatures.

\section{CONCLUSION}

In this work an STPV system design wherein the emitter and PV cell reside at the focal points of an ellipsoidal optical cavity is proposed. Results from numerical analysis demonstrate the ellipsoidal optical cavity greatly enhances the system efficiency by boosting the effective view factor, emitter temperature and photon recycling, whereby photons are returned to the emitter to increase its temperature. Furthermore, an annular reflector can be inserted at the mid-plane of the ellipsoidal optical cavity to tune the degree of photon recycling. Results show the efficiency of a STPV system can be increased from $2.38 \%$ for a hypothetical STPV system comprised of a GaSb PV cell and an absorber/emitter in a parallel plate configuration to $5.62 \%$ by using the ellipsoidal optical cavity. Furthermore, assuming the surface of the ellipsoidal optical cavity reflects $99 \%$ of the radiation incident onto its surface, efficiencies of $11.1 \%$ and $15.4 \%$ can be attained when the solar concentration factor is $700 \mathrm{X}$ and $1400 \mathrm{X}$, respectively. These results are attained for STPV systems without using selective emitters or filters. The proposed optical cavity reduces the PV cell area required to achieve high radiation-to-power conversion efficiencies, which is important for reducing the cost of TPV systems. Furthermore, the ellipsoidal optical cavity proposed in this study has the capability to reduce the conduction and radiation heat load on the PV cell, which should be kept at low operating temperatures. The ellipsoidal optical cavity can be integrated into the design of advanced TPV systems and bring them closer to the high theoretical efficiencies TPV systems are capable of. 


\section{APPENDIX}

See Appendix 1 for supporting content.

\section{REFERENCES}

[1] R. E. Nelson, "A brief history of thermophotovoltaic development," Semicond. Sci. Technol., vol. 18, no. 5, p.S141, 2003.

[2] T. Bauer, "Applications of TPV generators" in Thermophotovoltaics: basic principles and critical aspects of system design, Springer Science \& Business Media, 2011, pp. 147-188.

[3] T. Burger, C. Sempere, B. R. Layinde, A. Lenert, "Present Efficiencies and Future Opportunities in Thermophotovoltaics," Joule, vol. 4, no. 8, pp. 1660-1680, 2020.

[4] R. Seitz, B. O. Moller, A. Thielman, A. Sauer, M. Meister, M. Pero, O. Kleine, C. Rohde, A. Bierwisch, M. de Vries, V. Kayser, "Nanotechnology in the Sectors of Solar Energy and Energy Storage: Technology Report," International Electrotechnical Commission, 2013.

[5] N. P. Harder, and P. Würfel, "Theoretical limits of thermophotovoltaic solar energy conversion" Semicond. Sci. Technol., vol. 18, no. 5, p.S151, 2003.

[6] Z. Omair, L. M. Pazon-Outon, and E. Yablonovitch, "Practical challenges towards $50 \%$ efficient thermophotovoltaic energy conversion," Proc. SPIE vol. 11120, pp. 1112002, 2019.

[7] O. Dupré, R. Vaillon M. A. Green, "Optimization of solar thermophotovoltaic systems including the thermal balance," Proc. IEEEPVSC, 2016, pp. 1030-1033.

[8] A. Veeraragavan, L. Montgomery, A. Datas, "Night time performance of a storage integrated solar thermophotovoltaic (SISTPV) system," Sol. Energy, vol. 108, pp. 377-389, 2014.

[9] A. Datas, D. L. Chubb, A. Veeraragavan, "Steady state analysis of a storage integrated solar thermophotovoltaic (SISTPV) system," Sol. Energy, vol 96, pp. 33-45, 2013

[10]A. Datas, E. López, A. Ramos, N. Nikolopoulos, A. Nikolopoulos, M. Zeneli, N. Sobczak, W. Polkowski, M. Tangstad, J. Safarian, D. M. Trucchi, "Ultra-high temperature energy storage and conversion: A review of the AMADEUS project results," Proc. AIP, vol. 2303, pp. 190008, 2020.

[11]A. Datas, M. Zeneli, C. del Cañizo, I. Malgarinos, A. Nikolopoulos, N. Nikolopoulos, S. Karellas, A. Martí, "Molten silicon storage of concentrated solar power with integrated thermophotovoltaic energy conversion," Proc. AIP, vol. 2033, 2018, pp. 090005.

[12]A. Datas, and C. Algora, "Development and experimental evaluation of a complete solar thermophotovoltaic system," Prog. Photovoltaics Res. Appl, vol. 21, no. 5, pp. 1025-39, 2013.

[13]C. Ungaro, S.K. Gray, M.C. Gupta, "Solar thermophotovoltaic system using nanostructures," Opt. Express, vol. 23, no. 19, pp. 1149-56, 2015.

[14] A. Kohiyama, M. Shimizu, K. Konno, T. Furuhashi, H. Yugami, "Effective photon recycling in solar thermophotovoltaics using a confined cuboid emitter," Opt. Express, vol. 28, no. 26, pp. 38567-78, 2020.

[15]H. Wang, J.Y. Chang, Y. Yang, L. Wang, "Performance analysis of solar thermophotovoltaic conversion enhanced by selective metamaterial absorbers and emitters" Int. J. Heat Mass Transfer, vol. 1, pp. 788-98, 2016.

[16] Y. Wang, L. Zhou, Y. Zhang, J. Yu, B. Huang, Y. Wang, Y. Lai, S. Zhu, J. Zhu, "Hybrid Solar Absorber-Emitter by Coherence-Enhanced Absorption for Improved Solar Thermophotovoltaic Conversion," Adv. Opt. Mater., vol. 6, no. 24, pp. 1800813, 2018.

[17]C. C. Kelsall, "Cavity absorber-emitters for high-temperature solar thermophotovoltaics" M.Sc. Thesis, Dep. Mech. Eng., Massachusetts Institute of Technology, Cambridge, MA, USA, 2018.

[18]D. Cakiroglu, J.P. Perez, A. Evirgen, C. Lucchesi, P.O. Chapuis, T. Taliercio, E. Tournié, R. Vaillon, "Indium antimonide photovoltaic cells for near-field thermophotovoltaics," Sol. Energy Mater. Sol. Cells, no. 203, pp.110190, 2019.

[19] Y. Bi, A. Bertran, S. Gupta, I. Ramiro, S. Pradhan, S. Christodoulou, S.N. Majji, M.Z. Akgul, G. Konstantatos, "Solution processed infrared-and thermo-photovoltaics based on $0.7 \mathrm{eV}$ bandgap $\mathrm{PbS}$ colloidal quantum dots," Nanoscale, vol. 11, no. 3, pp. 838-843, 2019.

[20]Q. Lu, X. Zhou, A. Krysa, A. Marshall, P. Carrington, C. H. Tan, A. Krier, "InAs thermophotovoltaic cells with high quantum efficiency for waste heat recovery applications below 1000 C," Sol. Energy Mater. Sol. Cell, vol. 179 , pp. 334-8, 2018

[21] A. Zayan, M, Stevens, T.E. Vandervelde, "GaAsBi alloys for photovoltaic and thermophotovoltaic applications," Proc. IEEE, 2016, pp. 2839-2843.
[22]Y. Y. Lou, X. L. Zhang, A. B. Huang, Y. Wang, "Enhanced thermal radiation conversion in a $\mathrm{GaSb} / \mathrm{GaInAsSb}$ tandem thermophotovoltaic cell," Sol. Energy Mater. Sol. Cell, vol. 172, pp. 124-32, 2017.

[23] L. Tang, L. M. Fraas, Z. Liu, C. Xu, X. Chen, "The theoretical performance of GaInAsSb and GaSb cells versus IR emitter temperature in thermophotovoltaic systems," IEEE Trans. Electron Devices, vol. 63, no. 9, pp. 3591-8, 2016.

[24]C. Zhang, Z. Liao, L. Tang, Z. Liu, R. Huo, Z. Wang, K. Qiu, "A comparatively experimental study on the temperature-dependent performance of thermophotovoltaic cells," Appl. Phys. Lett., vol. 114, no. 19, pp. 193902, 2019.

[25]Z. Utlu, and B. S. Önal, "Performance evaluation of thermophotovoltaic GaSb cell technology in high temperature waste heat," Proc. IOP, vol. 307, 2018, pp. 012075.

[26] J. K. Tong, W. C. Hsu, Y. Huang, S. V. Boriskina, and G. Chen, "Thinfilm 'thermal well' emitters and absorbers for high-efficiency thermophotovoltaics" Sci. Rep., vol. 5, no. 1, pp. 1-12, 2015.

[27] M. Chirumamilla, G. V. Krishnamurthy, K. Knopp, T. Krekeler, M. Graf, D. Jalas, M. Ritter, M. Störmer, A. Y. Petrov, and M. Eich, "Metamaterial emitter for thermophotovoltaics stable up to 1400 C," Sci. Rep., vol. 9, no. 1, pp. 1-11, 2019.

[28] C. Wu, B. Neuner, J. John, A. Milder, B. Zollars, S. Savoy, and G. Shvets, "Metamaterial-based integrated plasmonic absorber/emitter for solar thermo-photovoltaic systems," J. Opt., vol. 14, no. 2, pp. 024005, 2012.

[29] A. Lenert, D. M. Bierman, Y. Nam, W. R. Chan, I. Celanović, M. Soljačić, and E.N. Wang, "A nanophotonic solar thermophotovoltaic device," Nat. Nanotechnol., vol. 9, no. 2, pp. 126-130, 2014.

[30]M. Shimizu, A. Kohiyama, H. Yugami, "High-efficiency solarthermophotovoltaic system equipped with a monolithic planar selective absorber/emitter," J. Photonics Energy, vol. 5, no. 1, pp. 053099, 2015.

[31]D. M. Bierman, A. Lenert, W. R. Chan, B. Bhatia, I. Celanović, M. Soljačić, E. N. Wang, "Enhanced photovoltaic energy conversion using thermally based spectral shaping," Nat. Energy, vol. 1, no. 6, pp. 16068, 2016.

[32]A. Kohiyama, M. Shimizu, H. Yugami, "Unidirectional radiative heat transfer with a spectrally selective planar absorber/emitter for highefficiency solar thermophotovoltaic systems," Appl. Phys. Express, vol. 9, no. 11 , pp. 112302, 2016.

[33]R. Bhatt, I. Kravchenko, M. Gupta, "High-efficiency solar thermophotovoltaic system using a nanostructure-based selective emitter," Sol. Energy, no. 197, pp. 538-545, 2020.

[34]R. Sakakibara, V. Stelmakh, W. R. Chan, M. Ghebrebrhan, J. D. Joannopoulos, M. Soljacic, I. Čelanović, "Practical emitters for thermophotovoltaics: a review", J. Photonics Energy, vol. 9, no. 3, pp. 032713, 2019.

[35]Z. Omair, G. Scranton, L.M. Pazos-Outón, T.P. Xiao, M.A. Steiner, V. Ganapati, P.F. Peterson, J. Holzrichter, H. Atwater, E. Yablonovitch, "Ultraefficient thermophotovoltaic power conversion by band-edge spectral filtering," Proc. National Academy of Sciences, vol. 116, no. 31, pp. 15356-61, 2019.

[36]A. Pirvaram, N. Talebzadeh, M. Rostami, S. N. Leung, P. G. O'Brien, "Evaluation of a ZrO2/ZrO2-aerogel One-Dimensional Photonic Crystal as an Optical Filter for Thermophotovoltaic Applications" Therm. Sci. Eng. Prog., pp. 100968, 2021.

[37]T. Zhou, Z. Sun, S. Li, H. Liu, and D. Yi, "Design and Optimization of Thermophotovoltaic System Cavity with Mirrors," Energies, vol. 9, no. 9, pp. 722, 2016.

[38]A. Steinfeld, and M. Schubnell, "Optimum aperture size and operating temperature of a solar cavity-receiver" Solar Energy, vol. 50, no. 1, pp. 19$25,1993$.

[39] A. Leroy, B. Bhatia, L. Zhao, E. N. Wang, "Specular side reflectors for high efficiency thermal-to-optical energy conversion," Opt. Express, vol. 26 , no. 10 , pp. $462-79,2018$.

[40]P. Sansoni, D. Fontani, F. Francini, D. Jafrancesco, G. Gabetta, M. Casale, R. Campesato, G. Toniato, "Evaluation of elliptical optical cavity for a combustion thermophotovoltaic system," Sol. Energy Mater. Sol. Cells, no. 171, pp. 282-92, 2017.

[41]E. Lindberg, L. Broman, "Fabergé optics and edge filter for a wood powder fuelled thermophotovoltaic system," Renew. Energy, vol. 28, no. 3, pp. 373-84, 2003.

[42]L. Weinstein, "Improvements to solar thermoelectric generators through device design,” Dep. Mech. Eng., Massachusetts Institute of Technology, Cambridge, MA, USA, 2013. 
[43]L. Weinstein, D. Kraemer, K. McEnaney, G. Chen, "Optical cavity for improved performance of solar receivers in solar-thermal systems," Sol. Energy, vol. 108, pp. 69-79, 2014.

[44] L. R. Arana, S. B. Schaevitz, A. J. Franz, M. A. Schmidt, and K. F. Jensen, "A microfabricated suspended-tube chemical reactor for thermally efficient fuel processing," J. Microelectromech. Syst., vol. 12, no. 5, pp. 600-612, 2003.

[45] W. M. Yang, S. K. Chou, C. Shu, Z. W. Li, and H. Xue, "Experimental study of micro-thermophotovoltaic systems with different combustor configurations," Energy Convers. Manage., vol. 48, no. 4, pp. 1238-1244, 2007.

[46] K. Zhu, Y. Zhang, Q. Cai, Q. Ye, X. Liu, X. Wu, "Performance Analysis of the Solar Thermophotovoltaics Systems Based on the Flat AbsorberEmitter with Nonuniform Temperature Distribution," Heat Transfer Res. no. 6,2021

[47]Y. Xuan, X. Chen, and Y. Han, "Design and analysis of solar thermophotovoltaic systems," Renew. Energy, vol. 36, no. 1, pp. 374-387, 2011.

[48] H. Wang, J. Y. Chang, Y. Yang, and L. Wang, "Performance analysis of solar thermophotovoltaic conversion enhanced by selective metamaterial absorbers and emitters," Int. J. Heat Mass Transfer, vol. 98, pp. 788-798, 2016.

[49]D. A. Kaminski, "Fluid Flow" Data Book, General Electric Company, $1^{\text {st }}$ ed., Boston, 1980.

[50]E. Ogbonnaya, and L., Weiss, "Small-Scale Flat Plate Collectors for Solar Thermal Scavenging in Low Conductivity Environments," Int. J. Photoenergy, 2017.

[51]M. Rostami, N. Talebzadeh, and P. G. O'Brien, "Transparent Photonic Crystal Heat Mirrors for Solar Thermal Applications," Energies, vol. 13, no. 6 , pp. 1464, 2020.

[52]M. Rostami, A. Pirvaram, N. Talebzadeh, P. G. O'Brien, "Numerical evaluation of one-dimensional transparent photonic crystal heat mirror coatings for parabolic dish concentrator receivers," Renewable Energy, no. 171, pp. 1202-1212, 2021.

[53] M. Rostami, N. Talebzadeh, P. G. O'Brien, "The Design of Infrared Mirror Coatings for the Enhanced Performance of Incandescent Lighting," Proc. CSME Conf., 2018. 